\title{
Psychological characteristics of art specialists with a highly productive creative imagination
}

\author{
Igor S. Dikiy*, Liudmila A. Dikaya, Viktorija V. Karpova, \\ Anastasiya Y. Lavreshina, and Margarita R. Kagramanyan \\ Southern Federal University, Rostov-on-Don, Russia \\ ${ }^{\star}$ Corresponding author. E-mail : isdikiy@sfedu.ru
}

Background: Notwithstanding all the different forms of art, the source of the creative process, its initial impulse, is an artistic image, and its creation is closely connected with the imagination. L. Vygotsky held the view that artistic creativity has great importance in overall development. In this regard, it is relevant to study the role of personal psychological characteristics that stimulate creativity, determine creative potential, and indicate personal predisposition to artistic activity.

Objective: to study individual psychological characteristics of art specialists with a highly productive creative imagination.

Design: There were 240 respondents: art specialists (artists, actors) and specialists who do not work in artistic fields. The empirical research included: assessment of the level of productivity of the creative imagination and psychological testing. All the participants, within the bounds of their profession, were divided into high productivity and low productivity groups. The productivity level of the creative imagination was assessed by expert judgment of art works made by the participants using a monotype technique. For psychological testing, the following methods were used: Freiburg Personality Inventory (FPI); Volitional Self-Control Inventory by A. Zverkov and E. Eidman; the "Choose the Side" test by E. Torrance; the "Unfinished Figures" subtest by E. Torrance; and the technique of pair comparisons by V. Skvortsov. Statistical data processing was conducted on the basis of percentage distribution and comparative analysis using the Student parametric t-test. We used STATISTICA 13.0 software.

Results: We found the following psychological characteristics of art specialists with highly productive creative imagination: high emotionality, inclination to affective reactions, high anxiety and excitability, and need for self-realization. Artists with highly productive creative imagination were characterized by immersion in their own emotions, psychic estrangement, high sensitivity, flexibility, ingenuity, right-hemisphere and combined types of thinking, and a high level of nonverbal creativity. Actors with highly productive creative imagination were characterized by stability, relaxation, selfsatisfaction, and average nonverbal creativity; the mixed type of thinking predominated in this group. 
Conclusion: The differences in the intensity of the psychological characteristics of representatives of these different professional groups may be determined by the level of productivity of their creative imagination. We discovered general and specific (depending on professional activity) psychological characteristics of art specialists with a high level of productivity of the creative imagination.

Keywords: artists, actors, creative imagination, monotype, volitional regulation, type of thinking, creativity

\section{Introduction}

Creativity is an integral part of human life, requiring mobilization of resources, knowledge, skills, and life experience. The character of the creative process depends on the particular features of the art form: poetry, painting, music, etc. L.S. Vygotsky (1998) held the view that artistic creativity has great importance in overall development. During the process of artistic activity, students master a new language to express their feelings, thoughts, and relationships; broaden their knowledge; foster feelings; and learn, with the help of an image, language that cannot be brought to consciousness in any other way.

Notwithstanding all the different art forms, the source of the creative process, its initial impulse, is an artistic image, and its creation is closely connected with the imagination. From the scientific point of view, imagination has traditionally been conceived as a mental process of creating new images through the transformation of perceptions and conceptions. The formation of an image according to its description is defined as reproductive imagination, and the formation of new, original images is defined as creative imagination (Petuhov, 1997).

The question of how a new image is created is one of particular interest and still requires specification. A. Melik-Pashaev regards artistic imagination as the ability to realize human orientation by the transformation of impressions that are caused by an aesthetic attitude to life, in expressive, sense-perceptible images (Melik-Pashaev, Novlyanskaya, Adaskina, \& Chubuk, 2005).

The scientific literature discusses the personal characteristics that contribute to realization of creative abilities, define creative potential, and indicate a personal predisposition to artistic activity (Batey \& Furnham, 2006; Benedek et al., 2012; Bogoyavlenskaya \& Bogoyavlenskaya, 2013; Silvia \& Beaty, 2012). Among the individual psychological characteristics of artists, researchers single out: emotionality, empathy, spontaneity, independence, inner freedom, and self-regulation (Feist, 1999; Rozhdestvenskaya, 1980).

Artistic giftedness, as well as general giftedness, is a systemic mental quality, the basis of which is not special abilities, but the intensity of integration processes "inside" the person, which shapes his personal sphere (Bogoyavlenskaya \& Bogoyavlenskaya, 2013). Personality as the main system-creating factor of giftedness may define the productivity of the creative imagination, the key phenomenon of artistic giftedness (Bogoyavlenskaya \& Bogoyavlenskaya, 2008). That is why the study of individual psychological characteristics of art specialists with different levels of productivity of the creative imagination is of interest. 


\section{Method}

\section{Aim, Hypotheses, and Participants}

The aim of the empirical research was to study individual psychological characteristics of art specialists with a high level of productivity of the creative imagination.

There were two hypotheses:

1. For art specialists with a high level of productivity of the creative imagination, both general and specific psychological characteristics may exist, depending on the field of their professional activity.

2. Differences in the intensity of psychological characteristics of representatives of different professional groups may be formed by the level of productivity of the creative imagination.

Participants comprised 240 right-handed respondents aged 23 to 27, both males and females. The participants were divided into three groups, according to their professional activities: artists ( 80 persons), actors ( 74 persons), and specialists who do not work in artistic fields (84 persons). The artistic specialists had higher education or specialized secondary education, and at least three years of work experience in their field.

The participants were briefed about the research procedure in advance and confirmed their voluntary agreement to take part in it.

\section{Empirical Research}

To develop our empirical research procedure, we started from Vygotsky's idea (1998), that through the analysis of art one can come to a psychological synthesis. First, an expert review was carried out of works of art created by participants. Then the subjects were given an array of psychological tests. We studied the psychological characteristics of the subjects, depending on the level of productivity of their creative imagination, as defined by the experts through analysis of the respondents' works of art.

Thus the empirical research procedure included:

- assessment of the subjects' level of productivity of the creative imagination;

- psychological testing.

The experts judged art works that were made by the participants using the monotype technique. Monotyping is a special form of art, which is considered to be an effective means for artistic image formation (Novikova, 2012).

Monotyping (from the Greek monos - one, only; and typos - stencil) is a graphic technique first used in the 17th century by the Italian artist and engraver Giovanni Castiglione, which involves stamping paint on paper. In the resulting mono- or polychrome paint-blots, an artistic image is detected and the missing details are added. Figure 1 presents examples of the monotypes and some artistic images based on them. 


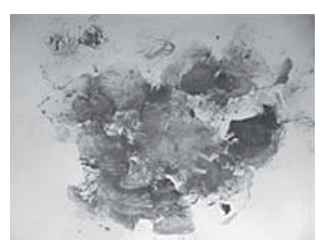

The monotype

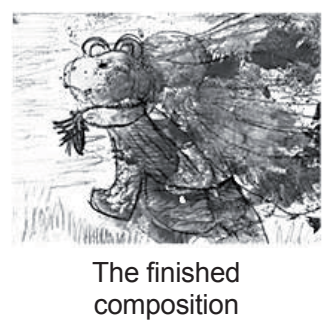

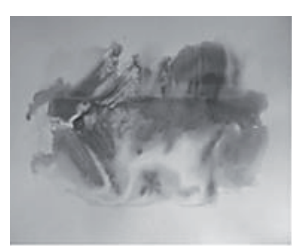

The monotype

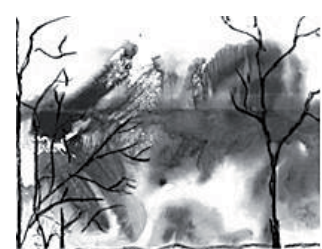

The finished composition

Figure 1. Examples of monotypes and finished compositions based on these artistic images

This technique has, in our view, certain advantages:

1. Monotypes not showing anything concrete are the threshold-extension stimuli, facilitating the process of creating free associations, ideas, and images. It should be noted that subjects' initial perceptions of the monotyping material do not really determine their concrete actions: The task may be the means of the artist's self-expression, or it may initiate the artistic process in a test subject as an externally induced behavior. We judge the external or internal sources of the artistic process by means of the expert opinion about the results of working with the paint-blots.

2. The ease of the task minimizes the level of laboratory stress, which could distort test subjects' ideas of their potential abilities. Monotyping can be used with test subjects who have no experience with artistic self-expression and otherwise don't know how to begin. Success in accomplishing the tasks does not depend directly on learning, which makes it possible to compare the results achieved by different people.

3. Monotyping suggests solving the task via insight, which makes it possible for us to register the steps of the artistic process.

4. The uniqueness of the stamps makes it impossible for subjects to prepare for the experiment beforehand. Thus we can state that the artistic process unfolds during the experiment itself and does not reflect any previous patterns of solving such a task.

The work of the participants in monotyping included:

1. Artistic image creation using one of the ten offered monotypes, working out its mental compositional elaboration;

2. Producing the planned artistic image on the sheet of paper with the selected monotype.

The level of productivity of the creative imagination of the participants was assessed by expert judgment of the art works created by respondents during the monotyping process (Dikiy, Dikaya, \& Karpova, 2014). The expert committee consisted of five professional art teachers who, in the course of many years (at least 15 years), have been permanent jurors of regional and all-Russian contests, taking part as experts on applicant selection committees of general secondary schools in Rostov-on-Don.

The criteria for assessing the level of productivity of the creative imagination proceeded from the idea that the process of creative imagination becomes appar- 
ent in the creation of an expressive image and in using appropriate means from a given art form in its implementation (Melik-Pashaev et al., 2005; Novikova, 2012). The expert judgment of the art works included two levels of estimation and was conducted in accordance with the following criteria:

1. The way an artistic image is created in monotyping:

- the use of monotyping as an image's foundation (1 point),

- the partial use of monotyping as an image's figure (2 points),

- the use of monotyping as the background for an idea and the development of a sensory image ( 3 points).

2. Expressiveness of the artistic image in the overall composition:

- degree of the composition's elaboration and completeness (1-3 points),

- technical quality of the picture: compositional order, treatment of light and shade, color match, dynamic characteristics (line directions, sense of rhythm) (1-4 points).

To ensure equal conditions for expert judgment of the work of artists and the work of participants without artistic experience, the assessment was carried out separately for the representatives of each professional group.

In conference with the expert committee, the criteria for assessing the art works' productivity level were fixed for each professional group. For specialists who do not work in artistic fields, the key criteria were total or partial use of monotyping as an image's foundation, and also the degree of elaboration and completeness of the composition. Highly productive participants were those who got at least a total of 4 points for these criteria. For actors, whose professional activity is connected with a process of artistic image formation, the key criteria of productivity were the way an artistic image was created and the degree of elaboration and completeness of the composition. Highly productive participants were those who used monotyping as the background for an idea and the development of a sensory image, and who had at least 2 points for the composition's elaboration. For artists, whose professional activity is connected not only with the process of artistic image formation, but also with technical means of realizing an idea on paper, the productivity estimation involved all the above-mentioned criteria. Highly productive participants were those who used monotyping as the background for an idea and the development of a sensory image, and who revealed the concept of the whole composition with the help of technique (at least a total of 8 points for these criteria).

All the participants, keeping within the bounds of their professional groups, were divided into high-productivity and low-productivity subgroups: an artist group - 50 high-productivity and 30 low-productivity participants; an actor group - 45 high-productivity and 29 low-productivity participants; a group of specialists who do not work in artistic fields - 49 high-productivity and 37 lowproductivity participants.

The psychological testing consisted of the following methods: Freiburg Personality Inventory (FPI) for detection of the main personality traits; the Volitional SelfControl Inventory by Zverkov and Eidman (1990) for detection of the volitional self-regulation level; the "Choose the Side" test by Torrance (1990) for detection of the prevailing type of thinking; the "Unfinished Figures" subtest by E. Torrance 
for detection of the level of nonverbal creativity (Tunik, 2013); the technique of pair comparisons by V. Skvortsov (Raigorodskii, 2011) for detection of the primary needs satisfaction level.

\section{Statistical data processing}

Statistical data processing was conducted on the basis of percentage distribution and comparative analysis with the Student parametric t-test. We used STATISTICA 13.0 computer software.

\section{Results}

\section{Personal characteristics of art specialists, depending on the level of productivity of their creative imagination}

Comparative analysis with the Freiburg Personality Inventory (FPI) distinguished the psychological characteristics of art specialists - artists and actors - with high and low levels of productivity of the creative imagination. Typical traits of all the artists included: high emotional lability, low emotional balance, and pronounced introversion.

Artists with a high level of productivity of the creative imagination, as opposed to those with a low level, had reliably higher average signs of neurosality (high degree of neurotism) $(\mathrm{p}<.01)$, irritability (high degree) $(\mathrm{p}<.01)$, shyness (high degree) $(\mathrm{p}<.05)$, spontaneous aggression (medium degree) $(\mathrm{p}<.01)$, reactive aggression (medium degree) $(\mathrm{p}<.01)$, depression (medium degree) $(\mathrm{p}<.01)$.

Actors with a high level of productivity of the creative imagination, as opposed to the artists with a low level, had reliably higher average signs of irritability (high degree) $(\mathrm{p}<.01)$, neurosality (medium degree) $(\mathrm{p}<.01)$, spontaneous aggression (medium degree) $(\mathrm{p}<.01)$, emotional balance (medium degree) $(\mathrm{p}<.05)$, emotional lability (high degree) $(\mathrm{p}<.01)$. (Figure 2$)$.

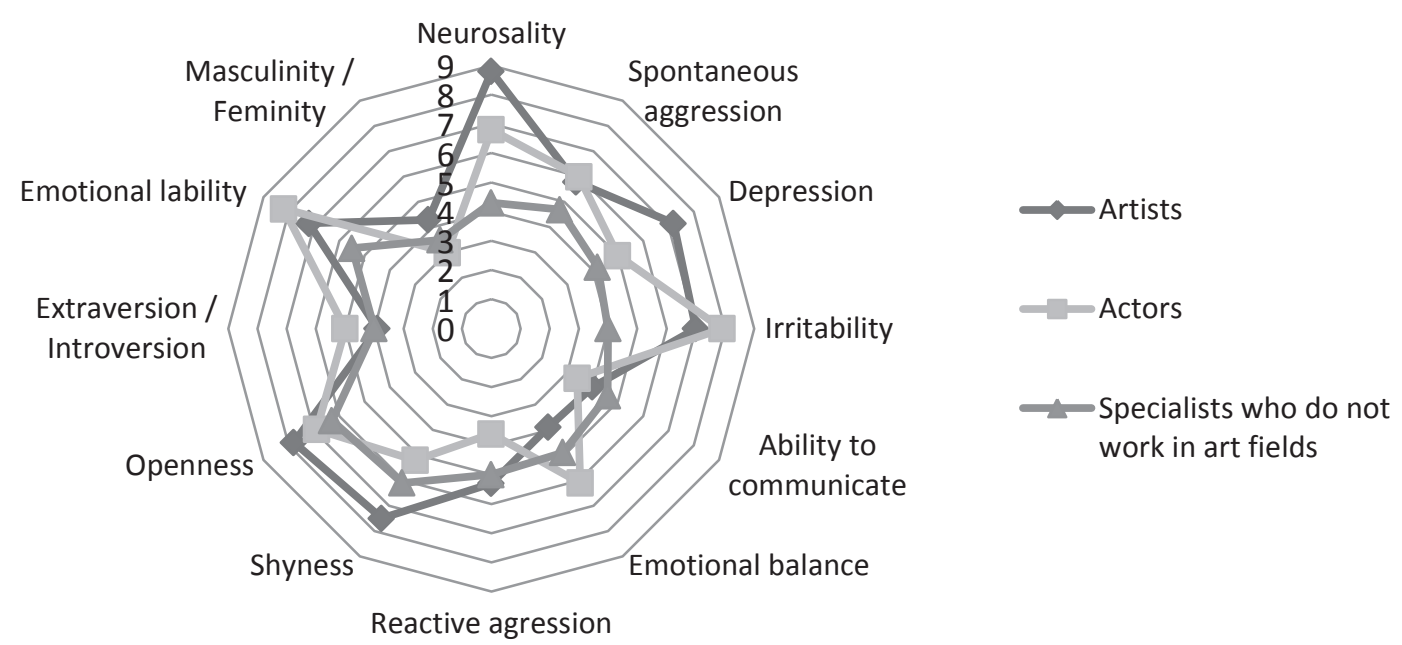

Figure 2. An average personal profile of representatives of different professional groups with a high level of productivity of the creative imagination

Note: - - reliable distinctions between appropriate indexes of specialists of different professional groups $(\mathrm{p}<.05)$. 
The results of the FPI for different specialists with a high level of productivity of the creative imagination, using the Student parametric t-test, indicated that the art specialists had reliably higher average values of irritability $(\mathrm{p}<.01)$ and emotional lability $(\mathrm{p}<.01)$ than did specialists who do not work in artistic fields. The average sign of neurosality $(\mathrm{p}<.01)$ was reliably higher in the artist group than in the two other groups; however, in the actor group, the values of neurosality $(\mathrm{p}<.01)$ were higher than in the group of participants who do not work in artistic fields.

Comparing two groups, artists and actors, we should mention that the average signs of depression were reliably higher in the artist group $(\mathrm{p}<.01)$; actors have reliably higher values of emotional balance $(\mathrm{p}<.01)$ (Figure 2$)$.

\section{Volitional self-regulation of art specialists, depending on the level of productivity of their creative imagination}

The artists with a high productivity level, as opposed to those with a low one, had reliably lower average values of total volitional self-regulation (low level) $(\mathrm{p}<.01)$, persistence (low level) $(\mathrm{p}<.01)$, and self-regulation (low level) $(\mathrm{p}<.01)$.

The actors with a high level of productivity of the creative imagination, as opposed to actors with a low level, had reliably lower average values of total volitional self-regulation (medium level) $(\mathrm{p}<.01)$ and of persistence (medium level) $(\mathrm{p}<.01)$.

The FPI of the specialists with a high level of productivity of the creative imagination, using the Student parametric t-test, indicated that the artists had reliably lower average values of volitional self-regulation $(\mathrm{p}<.01)$, persistence $(\mathrm{p}<.01)$, and self-regulation $(\mathrm{p}<.01)$ than those in the other two groups (Figure 3$)$.

Art specialists with a high level of productivity of the creative imagination, especially artists, had low reflection, but high sensitivity, flexibility, and ingenuity. Specialists with a high level of productivity who do not work in artistic fields, had steady intentions, a developed sense of duty, a high level of rational control, and realistic opinions.

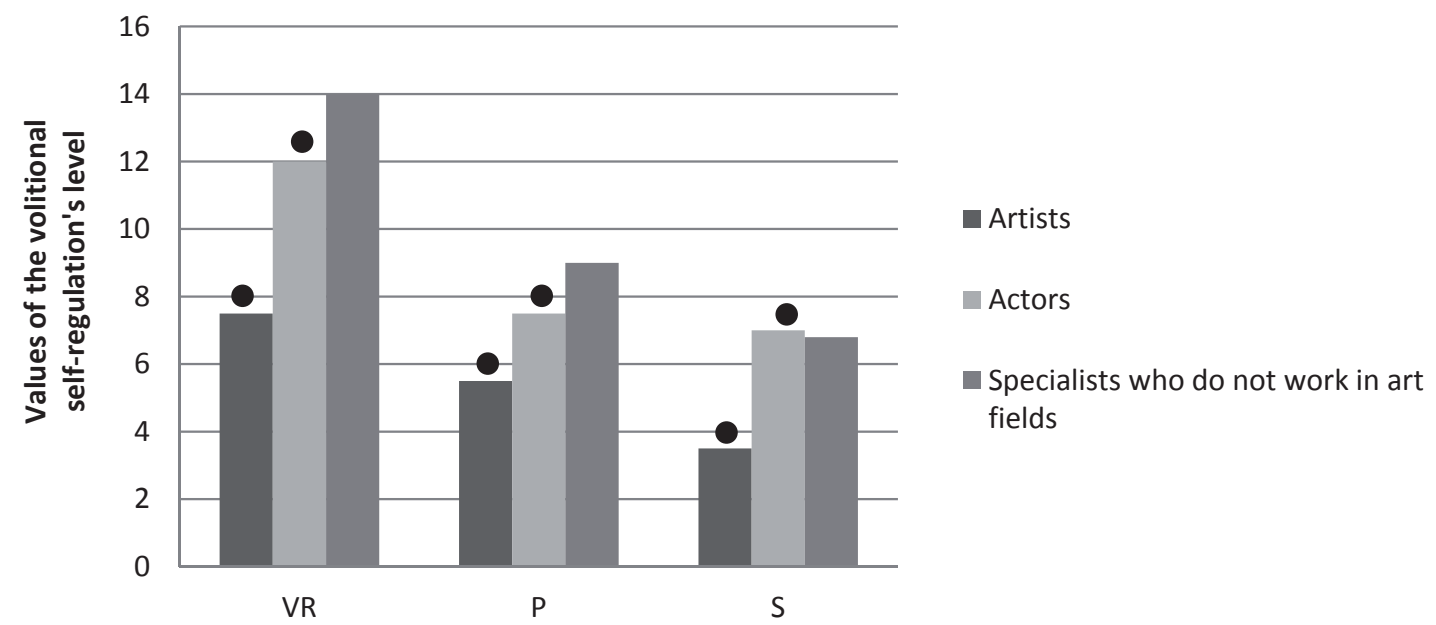

Figure 3. Average values of volitional self-regulation of representatives of different professional groups with a high level of productivity of the creative imagination

Note: VR — general level of volitional regulation; $\mathrm{P}$ - persistence; $\mathrm{S}$ - self-control; $\bullet$ - reliable distinctions between appropriate indexes of specialists of different professional groups $(p<.05)$. 


\section{Prevailing types of thinking of art specialists, depending on the level of productivity of their creative imagination}

Analysis of the distribution of the prevailing types of thinking among artists with a low level of productivity of the creative imagination reflected the distributive evenness of all types of thinking: right-hemisphere thinking - 27\% (8 persons); combined type $-23 \%$ ( 8 persons); mixed type $-33 \%$ (10 persons); and left hemisphere $-17 \%$ (5 persons).

$52 \%$ (26 persons) among artists with a high level of productivity of the creative imagination were characterized by a combined type of thinking; 40\% (20 persons) had a right hemisphere type, and a small number of artists (8\%, 4 persons) had a mixed type.

Analysis of the distribution of the prevailing types of thinking among actors with a low level of productivity of the creative imagination shows that $38 \%$ (11 persons) had a mixed type of thinking, $28 \%$ ( 8 persons) had a combined type, $24 \%$ ( 7 persons) had a left-hemisphere type, and $10 \%$ (3 persons) had a right-hemisphere type.

$49 \%$ (22 persons) among actors with a high level of productivity of the creative imagination were characterized by a mixed type of thinking, 24\% (11 persons) had a right-hemisphere type, and $27 \%$ (12 persons) had a combined type.

Generalizing the results of the distribution of the prevailing types of thinking among different subjects with high levels of productivity of the creative imagination, we may point out that the prevailing right-hemisphere type of thinking was discovered in all the groups, but in different percentages: $40 \%$ - artists, $24 \%-$ actors, $10 \%$ - specialists who do not work in artistic fields. The prevailing lefthemisphere type of thinking was typical of specialists who do not work in artistic fields (30\%). $52 \%$ of artists, $55 \%$ of specialists who do not work in artistic fields, and $27 \%$ of actors had a combined type of thinking. A mixed type of thinking was mainly pronounced in the actors group (49\%), but a small number of artists (8\%) and specialists who do not work in artistic fields (5\%) showed this type of thinking too (Figure 4).

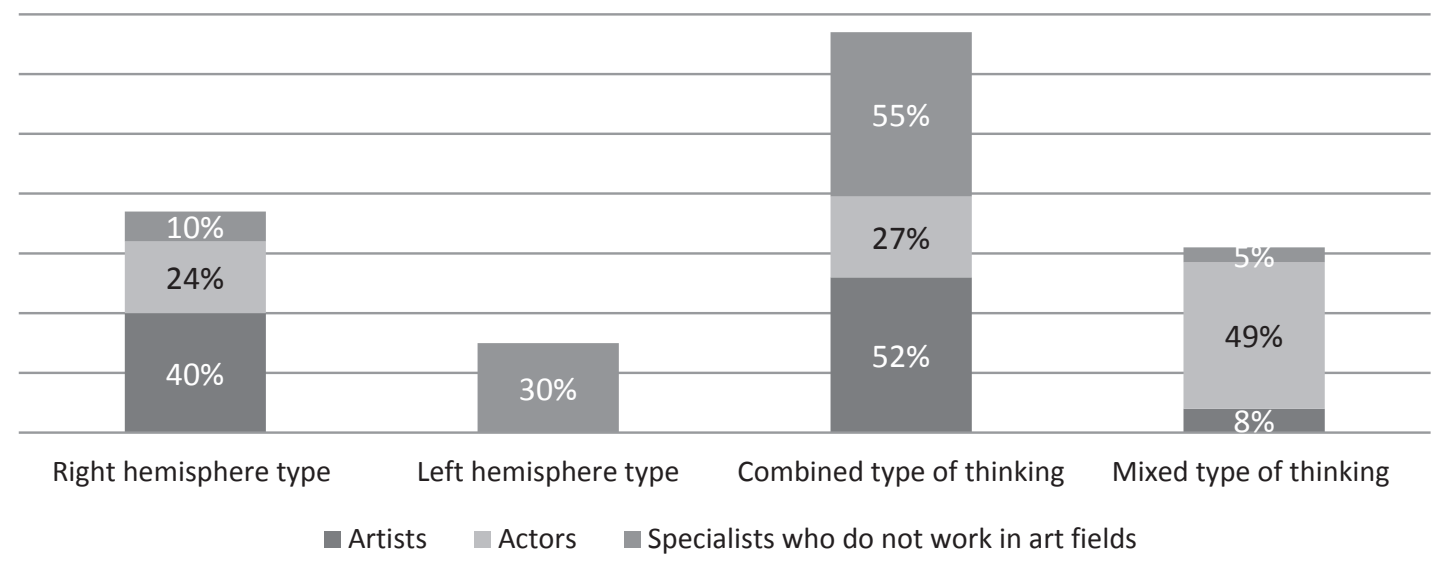

Figure 4. Distribution of the prevailing types of thinking among representatives of different professional groups with a high level of productivity of the creative imagination 


\section{Nonverbal creativity of art specialists, depending on the level of productivity of their creative imagination}

The distribution of nonverbal creativity among the art specialists, depending on the level of productivity of their creative imagination, had the following characteristics. The majority of artists with a low productivity level had an average level of nonverbal creativity - 90\% (27 persons); a small number of this group had an above average level of nonverbal creativity $-10 \%$ ( 3 persons). $50 \%$ ( 25 persons) of artists with a high level of productivity of the creative imagination had a high level of nonverbal creativity, $34 \%$ ( 7 persons) had a medium level, and 16\% (8 persons) had a higher than medium level.

Half of the representatives of the actor group with low (62\%, 18 persons) and high $(51 \%, 23$ persons) levels of productivity of the creative imagination had an average level of nonverbal creativity. The other actors with a low level had low $(24 \%, 7$ persons) and below average (14\%, 4 persons) levels of nonverbal creativity, and actors with high levels of productivity of the creative imagination were characterized by high $(24 \%, 11$ persons) and above average $(24 \%, 11$ persons) levels of nonverbal creativity.

Generalizing the results of the distribution of the nonverbal creativity levels among different specialists with high levels of productivity of the creative imagination, we should point out that low and below average levels of nonverbal creativity occur only in the group of specialists who do not work in artistic fields, whereas average, above average, and high levels of nonverbal creativity were discovered in all the groups, but in different percentages (Figure 5).

However, it is not enough to examine the quantitative characteristics of the distribution of nonverbal creativity in order to judge, by this test, nonverbal creativity's influence in the different professional groups on the productivity of the creative imagination. It is important to take into account that the test estimation of the total creativity level is conducted by summing up its separate signs - originality, elaboration, abstract name of a picture - which can have different correlations

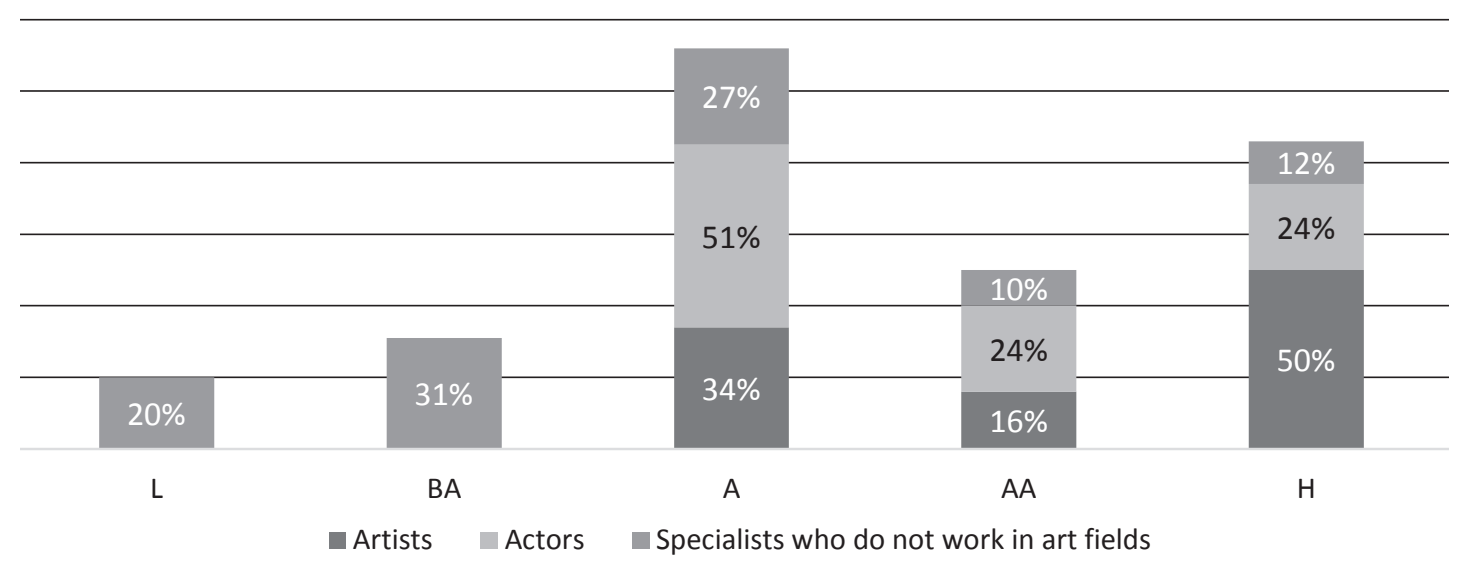

Figure 5. Distribution of nonverbal creativity among the representatives of different professional groups with a high level of productivity of the creative imagination

Note: L - low level of nonverbal creativity; BA - below average; A - average; AA - above average; $\mathrm{H}-$ high. 


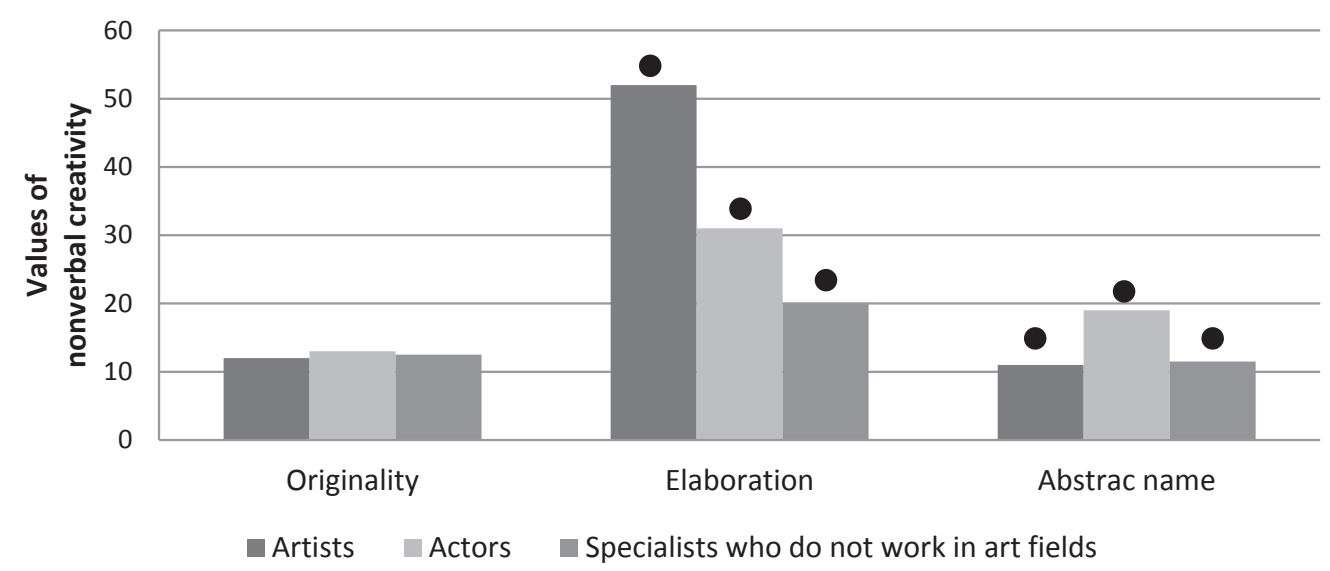

Figure 6. Average values of nonverbal creativity of the representatives of different professional groups with a high level of productivity of the creative imagination.

Note: - - reliable distinctions between appropriate indexes of specialists of different professional groups $(\mathrm{p}<.05)$.

in different professional groups and a different influence on preparation for the process of realizing creative imagination (Tunik, 2013).

As a result of the creativity indexes' comparison of different professional groups' representatives with a high level of productivity of the creative imagination, we discovered that the art specialists had reliably higher average values of the "elaboration" index $(\mathrm{p}<.01)$ than the specialists who do not work in this field. Comparing the artist and actor groups, we found that the "elaboration" index was reliably higher in the artist group ( $\mathrm{p}<.01)$, but the "abstract" index was reliably higher in the actor group $(\mathrm{p}<.01)$. In the different professional groups with a high level of productivity of the creative imagination, reliable differences for the "originality" index were not discovered (Figure 6).

The discovered differences among creativity values may indicate different perceptions and interpretations of the instructions ("complete the figures and think up names for each picture") by different specialists. For specialists who do not work in artistic fields, during the testing process the originality of the devised picture and its uniqueness were of great importance. The transference of the composition's main concept was important for art specialists; the completed figure was just part of the artistic design here. In connection with the specific character of their professional activity, the actors transferred ideas with the help of names and had higher "abstract name" indexes than the artists, but the artists used artistic means and had higher "elaboration" indexes than the actors.

\section{Prevailing needs of art specialists, depending on the level of productivity of their creative imagination}

As a result of the distribution analysis among specialists of different professional groups with a high level of productivity of the creative imagination, we discovered that in the artist group with a low productivity level, need for respect (40\%, 12 persons), and need for self-actualization as well as material needs (20\%, 6 persons) predominated. A small number of artists (10\%, 3 persons) felt the need for safety and interpersonal connection. 
Artists with low productivity level

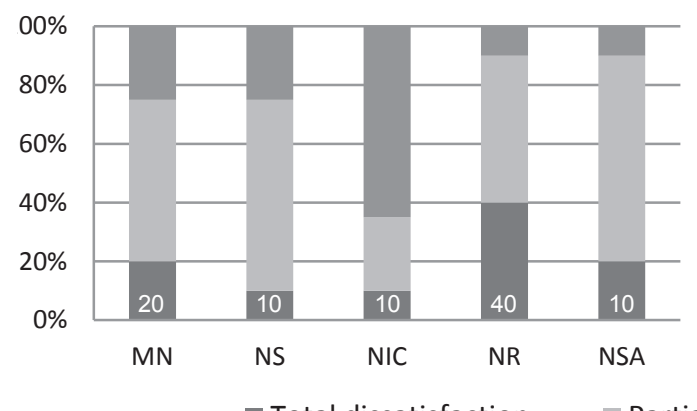

- Total dissatisfaction

\section{Artists with high productivity level}

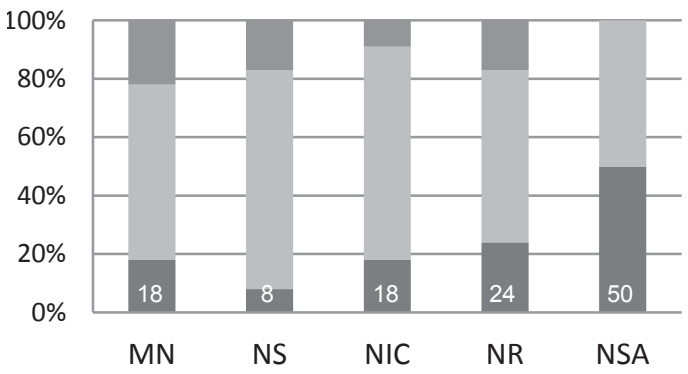

Figure 7. Distribution of the main needs among the artists with a high level of productivity of the creative imagination.

Note: $\mathrm{MN}$ - material needs; NS - need for safety; NIC - need for interpersonal connection; $\mathrm{NR}$ - need for respect; NSA - need for self-actualization.

The main needs of the artists with a high level of productivity of the creative imagination were:

- $\quad$ need for self-actualization (50\%, 25 persons);

- $\quad$ need for respect (24\%, 12 persons).

A small number of this group felt the need for interpersonal connection and material needs (18\%, 9 persons) and for safety ( $8 \%, 4$ persons) (Figure 7 ).

In the actor group with a low productivity level, need for respect $(48 \%, 14$ persons), need for self-actualization (52\%, 15 persons) and material needs (38\%, 11 persons) predominated. A small number of participants (10\%, 3 persons) pointed out interpersonal connection as an unsatisfied need (Figure 8).

Most actors had a prevailing need for self-actualization (62\%, 28 persons). And just a small number of representatives of the different groups (10\%, 3 persons) pointed out the need for respect $(13 \%, 6$ persons), interpersonal connection ( $11 \%$, 5 persons), and material needs (11\%, 5 persons) as unsatisfied needs (Figure 8).

Actors with low productivity level

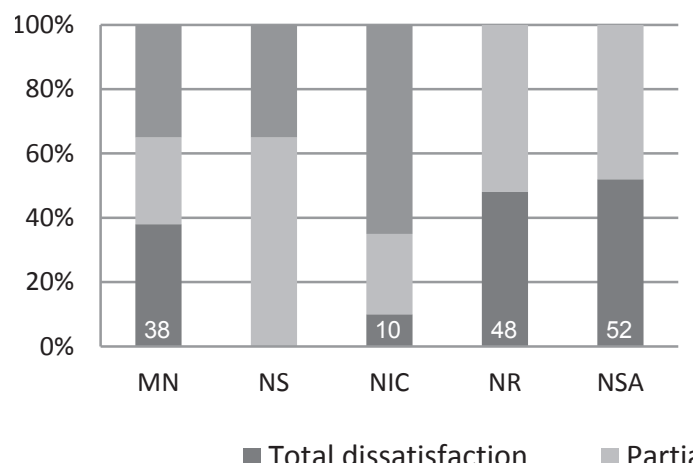

\section{Actors with high productivity level}

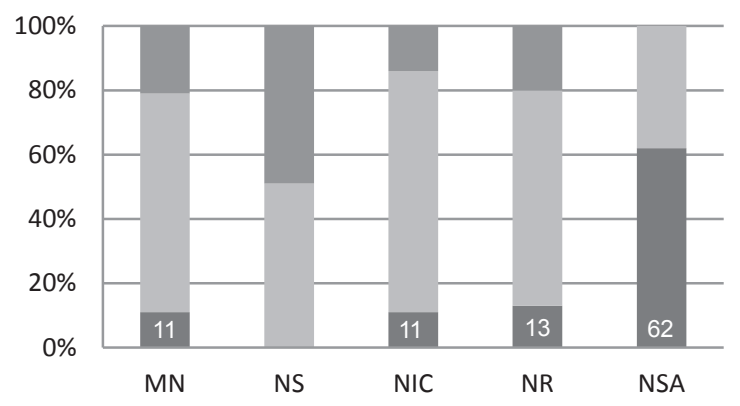

Figure 8. Distribution of the main needs among the actors with a high level of productivity of the creative imagination.

Note: $\mathrm{MN}$ - material needs; NS - need for safety; NIC - need for interpersonal connection; NR - need for respect; NSA - need for self-actualization. 
Summing up the main needs among the different groups with a high level of productivity of the creative imagination, we should mention that a great number of the art specialists had a prevailing need for self-actualization. A great number of the specialists (59\%, 29 persons) who do not work in artistic fields, and a quarter of the artists, had a prevailing need for respect and recognition.

\section{Discussion}

Our data correlate with those of other authors. Feist (1999) points out that art representatives have great emotionality, instability, and asociality. Rozhdestvenskaya (1980) singles out the sensitivity to slight changes in the external environment and emotional excitability among those with artistic giftedness. This conforms to our research data about high levels of neurosality, irritability, and emotional lability among the art specialists with a high level of productivity of the creative imagination.

Specific personal features of artists in their orientation to the inner world are reflected by the work of Pavlova (2014). In our research, in the artist group with a high level of productivity of the creative imagination, such psychological characteristics as immersion in emotional experience and tending to isolation were discovered. Among personal characteristics of an artist, Sobkin and Lykova (2014) mention emotional instability, sensibility of social influence, impressionability, empathy, with a parallel increase of ease in behavior (relaxation). In our research, we found such psychological characteristics of actors with high levels of productivity of the creative imagination as stability, relaxation, and satisfaction with oneself.

The low level of volitional self-regulation of artists with a high productivity level that we found in our work conforms to the data of Rozhdestvenskaya (1980), where a high level of reflection can fetter subconscious creative work and block the imagination. With their research into gifted children with disharmonious development, disorders of general regulation and will were mentioned by Bogoyavlenskaya \& Bogoyavlenskaya (2008). Gifted children are characterized by such personal qualities as perfectionism, which becomes apparent through high demands placed on themselves and entailing stress and anxiety.

The desire of artists for self-disclosure was revealed by Rozhdestvenskaya (1980) and is connected with the desire to influence people and transfer one's own worldview to them. An artist is dependent on the appreciation of his works by other people, on their opinions about his creative work. Probably this is connected with our finding of the combination of needs for respect and self-realization of artists with a high level of productivity of the creative imagination.

\section{Conclusion}

Relying on the results of this research, we come to the following conclusions:

1. The art specialists with a high level of productivity of the creative imagination were distinguished from other participants in that they were more emotional, inclined to affective reactions, highly anxious, and excitable. 
2. The artists with a high level of productivity of the creative imagination were characterized by immersion in their own emotions, psychic estrangement, high sensitivity, flexibility, and ingenuity. The majority of these artists were characterized by right-hemisphere and combined types of thinking, a high level of nonverbal creativity, where an "elaboration" sign is pronounced. The need for self-realization and respect is strongly marked.

3. The actors with a high level of productivity of the creative imagination were characterized by stability, relaxation, and self-satisfaction. A mixed type of thinking predominated in this group. The majority of these actors were characterized by an average level of nonverbal creativity, where an "abstract name" sign is pronounced. The need for self-actualization was strongly marked.

These results can be used in educational programs for art students, based on the harmonious combination of the development of productivity of the creative imagination with due regard for personal psychological qualities and for forming technical skills; this is true in the practice of art psychotherapy as well.

Possibilities for further investigation include studying the psychological characteristics of art specialists differentiated by age and sex.

\section{References}

Batey, M., \& Furnham, A. (2006). Creativity, intelligence, and personality: A critical review of the scattered literature. Genetic, Social, and General Psychology Monographs,132(4), 355429. https://doi.org/10.3200/MONO.132.4.355-430

Benedek, M., Franz, F., Heene, M., \& Neubauer, A. (2012). Differential effects of cognitive inhibition and intelligence on creativity. Personality and Individual Differences, 53, 480-485. https://doi.org/10.1016/j.paid.2012.04.014

Bogoyavlenskaya, D.B., \& Bogoyavlenskaya, M.E. (2013). Odarennost': priroda i diagnostika [Giftedness: Nature and diagnosis]. Moscow: Autonomous Non-profit Organization "Theoretical and Practical Centre of Development and Expert Examinations in Education".

Bogoyavlenskaya, D.B., \& Bogoyavlenskaya, M.E. (2008). Osobennosti razvitiya lichnosti s garmonichnym i disgarmonichnym tipami odarennosti [The particular features of personal development with harmonious and disharmonious types of giftedness]. Rossijskij psikhologicheskij zhurnal [Russian psychological journal], 5(4), 11-21.

Dikaya, L.A., \& Dikiy, I.S. (2015). Tvorcheskij mozg [The creative brain]. Rostov-on-Don: Southern Federal University Press.

Dikaya, L.A., \& Skirtach, I.A. (2015). Neurophysiological correlates of musical creativity: The example of improvisation. Psychology in Russia, 8(3), 84-98. https://doi.org/10.11621/ pir.2015.0307

Dikiy, I.S., Dikaya, L.A., \& Karpova, V.V. (2014). Inter- and intrahemispheric functional organization of brain cortex in artists during creative process. International Journal of Psychophysiology, 2(94), 161. https://doi.org/10.1016/j.ijpsycho.2014.08.706

Feist, G. J. (1999). Affect in artistic and scientific creativity. Affect, creative experience, and psychological adjustment, 93-108.

Melik-Pashaev, A.A., Novlyanskaya, Z.N., Adaskina A.A., \& Chubuk, N.F. (2005). Psikhologiya odarennosti: khudozhestvennaya odarennost [The psychology of giftedness: Artistic giftedness]. Moscow: Moscow Institute of Open Education. 
Novikova, N.A. (2012). Tvorcheskii podkhod v khudozsestvennom obrasovanii [A creative approach to art education]. Pedagogika iskusstva [Pedagogy of Art], (1), 235-245.

Pavlova, E.V. (2014). Psikhologicheskie i khudozsestvennye osobennosti kartiny mira u studentov-khudozhnikov i studentov drugikh specsial'nostei [Psychological and artistic characteristics of the worldview of art students and students of other specialties]. Molodoi uchenyi [Young scientist], (2), 689-693.

Petuhov, V.V. (1997). Voobrazhenie i poznanie [Imagination and cognition]. In Modeli mira [World patterns] (pp. 27-35). Moscow: Russian Association of Artificial Intelligence.

Raigorodskii, D.Y. (2011). Prakticheskaya psikhodiagnostika. Metodiki i testy [Practical psychodiagnostics. Procedures and tests] (pp. 624-626). Moscow: Bakhrakh-M.

Rozhdestvenskaya, N.V. (1980). Tvorcheskaia odarennost' i svoistva lichnosti (eksperimental'noe issledovanie akterskoi odarennosti) [Creative giftedness and personal characteristics (experimental study of actors' giftedness)]. In Psikhologiya processov khudozhestvennogo tvorchest$v a$ [The psychology of processes of artistic creativity] (pp. 57-67). Leningrad: Nauka.

Silvia, P.J., \& Beaty, R.E. (2012). Making creative metaphors: The importance of fluid intelligence for creative thought. Intelligence, 40(4), 343-351. https://doi.org/10.1016/j. intell.2012.02.005

Sobkin, V.S., \& Lykova, T.A. (2014). Specific features of personality changes among theatre college students during the first year. Journal of Siberian Federal University. Humanities \& Social Sciences, 12 (7). 2099-2109. https://doi.org/10.17516/1997-1370-2014-7-12-2099-2109

Torrance, E. (1990). Vseob'emluzhshchii mir [The allll-embracing world]. OMNI, 12(10).

Tunik, E.E. (2013). Luchshie testy na kreativnost'. Diagnostika tvorcheskogo myshleniya [The best creativity tests. Diagnosis of creative thinking]. St. Petersburg: Piter.

Vygotsky, L.S. (1991). Voobrazhenie i tvorchestvo v detskom vozraste [Imagination and creativity in children]. Moscow: Prosveschenie.

Vygotsky, L.S. (1998). Psikhologiya iskusstva [Psychology of art]. Rostov-on-Don: Fenix.

Zverkov, A.G., \& Eidman, E.V. (1990). Diagnostika volevogo samokontrolya (oprosnik VSK) [Diagnosis of voluntary self-control (VSK questionnaire). In Praktikum po psikhodiagnostike. Psikhodiagnostika motivatsii i samoregulyatsii. [Workshop on psychodiagnostics. Psychodiagnostics of motivation and self-regulation] (pp. 116-124). Moscow: Moscow University Press.

Original manuscript received July 10, 2016 Revised manuscript accepted January 8, 2018

First published online June 30, 2018 